\title{
Journal Club: Florbetapir imaging in cerebral amyloid angiopathy-related hemorrhages
}

Andreas Charidimou, MD, PhD, Anne-Katrin Giese, MD, Marco Pasi, MD, Susanne J. van Veluw, PhD, Li Xiong, MD, PhD, Panagiotis Fotiadis, BSc, Sandro Marini, MD, Markus D. Schirmer, PhD, and Anand Viswanathan, MD, PhD

Neurology ${ }^{\circledR}$ 2018;91:574-577. doi:10.1212/WNL.0000000000006195

Cerebral amyloid angiopathy (CAA) is a common type of cerebral small vessel disease and a key cause of spontaneous lobar intracerebral hemorrhage (ICH) in the elderly. ${ }^{1,2}$ Currently, the clinical diagnosis of probable CAA is based on characteristic imaging findings including strictly lobar ICH and CAA-associated hemorrhagic lesions (e.g., cerebral microbleeds [CMB] and cortical superficial siderosis). Despite their high specificity for CAA, ${ }^{3}$ these lesions only provide indirect evidence of advanced disease. Currently, a definite CAA diagnosis can only be obtained on a brain biopsy or with a neuropathologic examination of the brain postmortem. Quantifying potential early stages of CAA in vivo through more direct biomarkers remains challenging. ${ }^{4}$ In order to assess the diagnostic yield of a direct amyloid PET tracer in the clinical setting, in the Journal club article "Florbetapir imaging in cerebral amyloid angiopathy-related hemorrhages," Raposo and colleagues compared cortical florbetapir-PET retention between patients with CAA-related ICH and patients with hypertension-related deep ICH. The authors report increased cortical florbetapir-PET uptake in patients with CAA-related ICH compared to those with deep ICH. However, its diagnostic value in acute CAA-related ICH was proved to be limited by its moderate sensitivity and specificity. While these data do not yet have direct implications for CAA in clinical practice, they are useful in consolidating evidence on amyloidPET performance in the setting of symptomatic CAA-related lobar ICH and may be informative for guiding future studies and trials in CAA. ${ }^{4}$

\section{Hypothesis and design}

The authors hypothesized that patients with CAA-related ICH may have higher cortical florbetapir retention and an occipital predominance compared to patients with deep ICH. They hypothesized that the increased retention may provide high diagnostic value to identify those ICH patients with CAA. The study prospectively enrolled 33 patients with acute symptomatic $\mathrm{ICH}$ from a single center.

\section{Methods}

This case-control study prospectively enrolled patients with acute spontaneous symptomatic ICH and classified them into 2 groups: lobar ICH patients fulfilling the modified clinical-MRI Boston criteria for probable $\mathrm{CAA}^{5,6}$; and deep ICH, as a comparison group. Patients with preexisting cognitive impairment, as determined by a score of $\geq 3.4$ on the Informant Questionnaire on Cognitive Decline in the Elderly (IQCODE), were excluded from the study. All patients had to have undergone $3 \mathrm{~T}$ MRI with blood-sensitive sequences (i.e., T2*-weighted gradient-recalled echo), to allow for CAA classification according to the Boston diagnostic criteria, and based on the presence of strictly lobar $\mathrm{CMB}$, a putative hemorrhagic small vessel disease marker. Patients underwent 3T MRI approximately 15 days post-ICH (median, interquartile range $[\mathrm{IQR}]$ 9-28 days). MRI scans were then used to classify patients and assess small vessel disease neuroimaging markers according to Standards for Reporting

\author{
Correspondence \\ Dr. Charidimou \\ andreas.charidimou.09@ \\ ucl.ac.uk
}


Vascular Changes on Neuroimaging recommendations, blinded to all other clinical or PET data.

To examine the burden and regional pattern of amyloid in the brain of these patients, the authors appropriately performed amyloid-PET imaging with ${ }^{18} \mathrm{~F}$-florbetapir at an average 39 days (IQR 21-93 days) post-ICH, using standard methodology. Data were processed using FSL (fmrib.ox.ac.uk/fsl) in 3D T1-weighted images. Probability maps were generated with the FMRIB Automated Segmentation Tool (FSL library tools) using appropriate standard thresholding, coregistration of CT scan space onto T1 space, transformation matrixes, and anatomic regions of interest (ROIs). Global cortical and regional standardized uptake value ratio (SUVr) of florbetapir, which allows quantification of amyloid burden in the brain, was analyzed for each patient and compared between the 2 groups using $t$ tests.

Florbetapir mean cortical retention was compared in 15 patients with acute CAA-related lobar ICH (mean age $63.7 \pm$ $12,40 \%$ female) and 18 patients with acute hypertensionrelated deep $\mathrm{ICH}$ (mean age $63.1 \pm 11,27.8 \%$ female). The contralesional (i.e., ICH-free) hemispheres of all participants were blindly assessed by 2 independent raters (who showed excellent interrater agreement, $\kappa=1$ ), categorizing the PET florbetapir images as either florbetapir-positive or florbetapirnegative. To assess the performance of florbetapir, the area under the curve (AUC) and sensitivity and specificity for global florbetapir were estimated.

For basic definition of the terms mentioned in the article, see the table.

\section{Results}

The main results were that cortical florbetapir-PET uptake was increased in patients with CAA-related $\mathrm{ICH}$ compared to those with deep ICH. The $2 \mathrm{ICH}$ groups were similar in their vascular risk factor profile (compared using Student $t$ tests or Mann-Whitney $U$ tests for normally and non-normally distributed continuous variables and $\chi^{2}$ tests for categorical variables) with the exception of hypertension and APOE genotype. Hypertension was more prevalent in the deep $\mathrm{ICH}$ group and the APOE $\varepsilon 2$ or APOE \&4 genotype was more prevalent in the CAA-ICH cohort. These differences in clinical characteristics are expected, given that the majority of deep ICHs are driven by hypertension or associated with vascular risk factor pathologies, while $A P O E$ is implicated in vascular amyloid accumulation pathophysiology.

Global cortical florbetapir retention was higher in CAA-ICH patients compared to deep ICH patients (SUVr $1.27 \pm 0.12$ vs $1.12 \pm 0.12, p=0.001$, Cohen $d=1.25)$. Similarly, in univariable regional ROI analysis, florbetapir retention was higher in all individual cortical regions of the CAA-ICH patients when compared to the deep $\mathrm{ICH}$ patients. Among patients with CAA, the highest SUVr was estimated in the occipital lobe $(1.31 \pm 0.16)$. Of note, the occipital/whole cortex ratio was not different between CAA-ICH vs deep ICH patients $(1.03 \pm 0.07$ vs $1.02 \pm 0.05, p=0.656)$.

The AUC for distinguishing CAA-ICH and deep ICH was 0.811 (95\% confidence interval [CI] 0.642-0.980). At the SUVr threshold of 1.18 , the sensitivity to differentiate CAA$\mathrm{ICH}$ and deep ICH was 0.733 (95\% CI 0.475-0.893) and the specificity was 0.833 (95\% CI 0.598-0.948). Of all CAA-ICH patients, $60 \%$ (95\% CI $0.352-0.848)$ were florbetapirpositive, in comparison to only $11 \%$ (95\% CI $0.034-0.256$ ) in the deep ICH group, based on visual analysis.

\section{Discussion}

The authors explored florbetapir, a well-established amyloid radioligand commonly used in Alzheimer disease, and examined its presence and spatial distribution in acute CAAICH patients vs deep ICH patients. The study confirms recent findings that florbetapir binding is increased in patients with CAA-related lobar ICH compared to patients with hypertension-related deep $\mathrm{ICH}^{7}$ The authors appropriately conclude that the use of florbetapir-PET does not seem to increase sensitivity or specificity for CAA diagnosis, beyond the modified Boston criteria, ${ }^{6}$ and therefore has limited diagnostic value in clinical practice. Key strengths of the study include the combination of MRI and PET in the first weeks after ICH to evaluate CAA and comprehensive data on sensitivity and specificity of florbetapir to evaluate this new tracer as a potential diagnostic tool for the in vivo identification of CAA.

The findings of this interesting and elegant study need to be considered in the context of potential limitations, some of which are inherent to amyloid-PET studies in the field, ${ }^{8}$ while others are more related to the selected methodology. The main points relevant for interpretation include the following:

1. The selection of the study sample may have resulted in a potential selection bias, which potentially limits generalizability of the results. For example, the reported mean NIH Stroke Scale score and hematoma volumes are relatively low, suggesting a clinically mild $\mathrm{ICH}$ population. The mean age of this sample is also relatively low (63.7 years), compared to previously reported CAA cohorts ( $\sim 70$ years). ${ }^{9}$ PET imaging is likely better tolerated in relatively young and mildly affected patients with ICH. These factors may limit the study's generalizability, and hence these results might only be applicable to selected clinically mild ICH cases that do not represent the main bulk of patients seen in stroke clinics.

2. The selection of the deep $\mathrm{ICH}$ comparison group raises some concerns. Patients who presented with deep ICH who happened to have lobar $\mathrm{CMBs}$ may have been included in the control group since lobar CMBs are not 
Table Basic definitions of epidemiologic terms and methods mentioned in the reviewed article

\begin{tabular}{ll}
\hline Term & Definition \\
\hline Small vessel disease terms & \\
\hline Cerebral amyloid angiopathy & $\begin{array}{l}\text { A chronic degenerative disease characterized by progressive deposition of } \beta \text {-amyloid in the } \\
\text { media and adventitia of leptomeningeal vessels, small arteries, arterioles, and sometimes } \\
\text { capillaries in the cerebral cortex. It commonly results in strictly lobar intracerebral hemorrhage } \\
\text { and cerebral microbleeds in the elderly. }\end{array}$ \\
\hline Cerebral microbleeds & $\begin{array}{l}\text { Small (generally 2-5 mm in diameter, but sometimes up to } 10 \mathrm{~mm} \text { ) areas of signal void with } \\
\text { associated blooming seen on T2*-weighted MRI or other sequences that are sensitive to } \\
\text { susceptibility effects. Results of some studies suggest that MRI-visible microbleeds correspond } \\
\text { to hemosiderin-laden macrophages in perivascular tissue, consistent with vascular leakage of } \\
\text { blood cells affected by small vessel disease. }\end{array}$
\end{tabular}

\begin{tabular}{ll}
\hline Imaging analysis terms & Dividing a scan (i.e., T1-weighted) into multiple anatomic structures of interest. \\
\hline Segmentation & $\begin{array}{l}\text { Maps where the intensity value of each voxel (i.e., 3D pixel) represents the probability that it } \\
\text { belongs to gray matter. }\end{array}$ \\
\hline Gray matter probability map & $\begin{array}{l}\text { Aligning an MRI sequence to another sequence using a transformation matrix, as to establish } \\
\text { direct correspondence between their anatomical features. }\end{array}$ \\
\hline PET & $\begin{array}{l}\text { A nuclear medicine functional imaging technique that is used to observe metabolic processes in } \\
\text { the body. The system detects pairs of gamma rays emitted indirectly by a positron-emitting } \\
\text { radionuclide (tracer), which is introduced into the body on a biologically active molecule. 3D } \\
\text { images of tracer concentration within the body are then constructed by computer analysis. }\end{array}$ \\
\hline${ }^{18}$ F-florbetapir & $\begin{array}{l}\text { PET scanning radioligand compound containing the radionuclide fluorine-18, recently Food and } \\
\text { Drug Administration-approved as a diagnostic tool for Alzheimer disease. Florbetapir, like } \\
\text { Pittsburgh compound B (PiB), binds to } \beta \text {-amyloid; however, fluorine-18 has a half-life of } 109.75 \\
\text { minutes, in contrast to PiB's radioactive half-life of } 20 \text { minutes. }\end{array}$
\end{tabular}

\section{Statistical terms}

Specificity

True negative rate: Number of true negatives/(number of true negatives + number of falsepositives).

$\begin{array}{ll}\boldsymbol{t} \text { Test } & \begin{array}{l}\text { Statistical test most commonly applied when the test statistic would follow a normal } \\ \text { distribution. The } t \text { test can be used, for example, to determine if } 2 \text { normally distributed sets of } \\ \text { data are significantly different from each other. }\end{array}\end{array}$

Receiver operating characteristic (ROC)

An ROC curve plots true positive rate (sensitivity) and false-positive rate (100 - specificity) against each other. The closer the curve is to the upper left corner, the higher is the accuracy of the measure tested.

Area under the curve (AUC)

An AUC measures performance of a measure (how well measure can distinguish case/control or disease/normal). AUC can range from 0.5 (no better than chance) to 1 (perfect classification).

listed as an exclusion criterion. Hence, deep ICH patients harboring more severe hypertensive microangiopathy (with both deep and lobar microbleeds) or incipient CAA pathology (causing some of the lobar microbleeds) might have been part of the control group, with implications for amyloid-PET burden and distribution. Microbleeds are quite common in $\mathrm{ICH}$ patients ${ }^{10}$ and the Raposo et al. article does not clarify this important point. In fact, florbetapir PET may be useful in quantifying amyloid burden in patients who present with both CAA and hypertensive small vessel disease pathology (i.e., mixed $\mathrm{ICH} /$ microbleeds cases in different combinations, a common diagnostic dilemma ${ }^{8}$ ) - these cases, as in previous studies, were not explicitly included as a separate well-defined group in the analysis.

3. The authors state in the Discussion that the current findings suggest that florbetapir binds vascular amyloid in CAA. However, this conclusion should be interpreted with caution, as it is not directly supported by the study design. Amyloid PET tracers that specifically bind vascular amyloid are not available yet, despite some promising recent developments. ${ }^{8}$ Florbetapir PET, similar to other currently used amyloid tracers, is not specific for vascular amyloid, but instead binds both vascular and parenchymal amyloid, which often coexist in an older brain. It cannot be excluded that the different florbetapir retention values observed between the 2 groups might also be affected by factors beyond CAA, such as the coexistence of parenchymal amyloid, which is not entirely unlikely given the older age of the CAA-ICH group. The use of the IQCODE to exclude patients with pre-ICH cognitive impairment-such patients could have increased the chance of a false-positive findingmight not have been sufficient to overcome this issue.

4. The use of an additional control group (e.g., Alzheimer disease patients or young healthy controls) would have 
been interesting in disentangling the burden and patterns of florbetapir-PET. ${ }^{8}$

Beyond these limitations (many of them thoroughly discussed in the article), this work is important for the advancement of the field and will be useful in informing future studies on the diagnostic yield of amyloid-PET in CAA. Overall, the results point to the general consensus of the use of amyloid-PET in the setting of symptomatic CAA: a negative florbetapir-PET scan in a case with lobar or deep hemorrhages may rule out CAA as the underlying etiology, but a positive florbetapirPET scan remains challenging to interpret, since the signal may come from vascular or parenchymal amyloid deposits. The interested reader is directed to a recent systematic review of amyloid-PET studies in CAA, including gaps and directions for future research in the field. ${ }^{8}$

\section{Author contributions}

All coauthors actively participated in a structured discussion and critical appraisal of this paper at the Hemorrhagic Stroke Research Group Fellows Journal Club meeting. Andreas Charidimou: writeup, critical revisions. Anne-Katrin Giese: writeup, critical revisions. Marco Pasi: writeup, critical revisions. Susanne van Veluw: writeup, critical revisions. Li Xiong: writeup, critical revisions. Panagiotis Fotiadis: critical revisions. Markus D. Schirmer: critical revisions. Sandro Marini: critical revisions. Anand Viswanathan: critical revisions, supervision of the journal club and the report.

\section{Study funding}

No targeted funding reported.

\section{Disclosure}

The authors report no disclosures relevant to the manuscript. Go to Neurology.org/N for full disclosures.

\section{References}

1. Charidimou A, Gang Q, Werring DJ. Sporadic cerebral amyloid angiopathy revisited: recent insights into pathophysiology and clinical spectrum. J Neurol Neurosurg Psychiatry 2012;83:124-137.

2. Charidimou A, Boulouis G, Gurol ME, et al. Emerging concepts in sporadic cerebral amyloid angiopathy. Brain 2017;140:1829-1850.

3. Greenberg SM, Vernooij MW, Cordonnier C, et al. Cerebral microbleeds: a guide to detection and interpretation. Lancet Neurol 2009;8:165-174.

4. Greenberg SM, Salman RA, Biessels GJ, et al. Outcome markers for clinical trials in cerebral amyloid angiopathy. Lancet Neurol 2014;13:419-428.

5. Knudsen KA, Rosand J, Karluk D, Greenberg SM. Clinical diagnosis of cerebral amyloid angiopathy: validation of the Boston criteria. Neurology 2001;56:537-539.

6. Linn J, Halpin A, Demaerel P, et al. Prevalence of superficial siderosis in patients with cerebral amyloid angiopathy. Neurology 2010;74:1346-1350.

7. Gurol ME, Becker JA, Fotiadis P, et al. Florbetapir-PET to diagnose cerebral amyloid angiopathy: a prospective study. Neurology 2016;87:2043-2049.

8. Farid K, Charidimou A, Baron JC. Amyloid positron emission tomography in sporadic cerebral amyloid angiopathy: a systematic critical update. Neuroimage Clin 2017;15:247-263.

9. Charidimou A, Imaizumi T, Moulin S, et al. Brain hemorrhage recurrence, small vessel disease type, and cerebral microbleeds: a meta-analysis. Neurology 2017;89:820-829.

10. Pasquini M, Benedictus MR, Boulouis G, Rossi C, Dequatre-Ponchelle N, Cordonnier C. Incident cerebral microbleeds in a cohort of intracerebral hemorrhage. Stroke 2016;47:689-694.

\section{Sign Up for the AAN's Axon Registry}

The AAN encourages its US members to show their interest in participating in the Axon Registry ${ }^{\circledR}$ by signing up today.

Use the Axon Registry to:

- Simplify reporting requirements under MACRA's Quality Payment Program and avoid penalties while reducing your administrative burden

- Meet your MOC Part IV requirements and waive up to eight credits of Part II Self-Assessment

- Choose from 22 AAN neurology-specific quality measures that fit your practice

- Use data to understand your practice and identify where improvements can be made to patient care

- Manage your patients at a population level; look at a specific group of patients based on conditions, risk factors, demographics or outcome

- Demonstrate your value to payers when negotiating reimbursement

- Enjoy multi-year, fee-free access when you sign the agreements and integrate your EHR with the registry

Learn more at AAN.com/view/Axon and send your questions to registry@aan.com. 


\section{Neurology}

\section{Journal Club: Florbetapir imaging in cerebral amyloid angiopathy-related hemorrhages \\ Andreas Charidimou, Anne-Katrin Giese, Marco Pasi, et al. Neurology 2018;91;574-577 \\ DOI 10.1212/WNL.0000000000006195}

This information is current as of September 17, 2018

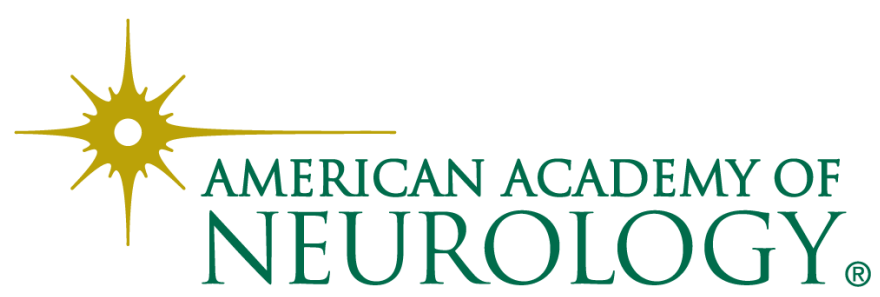




\section{Updated Information \& Services}

References

Citations

Subspecialty Collections

\section{Errata}

\section{Permissions \& Licensing}

\section{Reprints}

including high resolution figures, can be found at:

http://n.neurology.org/content/91/12/574.full

This article cites 10 articles, 6 of which you can access for free at: http://n.neurology.org/content/91/12/574.full\#ref-list-1

This article has been cited by 1 HighWire-hosted articles: http://n.neurology.org/content/91/12/574.full\#\#otherarticles

This article, along with others on similar topics, appears in the following collection(s):

\section{All Cerebrovascular disease/Stroke}

http://n.neurology.org/cgi/collection/all_cerebrovascular_disease_strok e

All Education

http://n.neurology.org/cgi/collection/all_education

Intracerebral hemorrhage

http://n.neurology.org/cgi/collection/intracerebral_hemorrhage

MRI

http://n.neurology.org/cgi/collection/mri

PET

http://n.neurology.org/cgi/collection/pet

An erratum has been published regarding this article. Please see next page or:

/content/93/2/e88.3.full.pdf

Information about reproducing this article in parts (figures,tables) or in its entirety can be found online at:

http://www.neurology.org/about/about_the_journal\#permissions

Information about ordering reprints can be found online:

http://n.neurology.org/subscribers/advertise

Neurology ${ }^{\circledR}$ is the official journal of the American Academy of Neurology. Published continuously since 1951, it is now a weekly with 48 issues per year. Copyright (O 2018 American Academy of Neurology. All rights reserved. Print ISSN: 0028-3878. Online ISSN: 1526-632X.

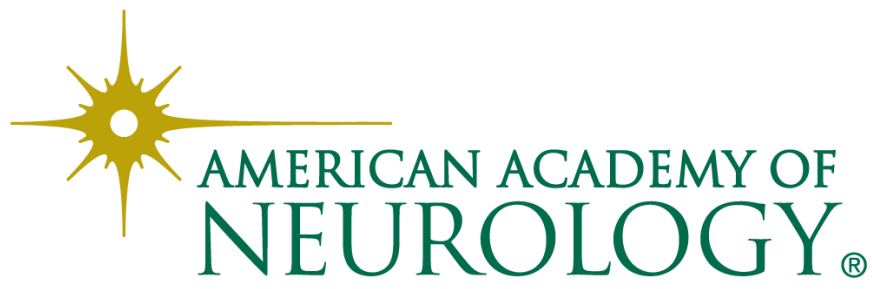




\title{
Disputes \& Debates: Editors' Choice
}

\author{
Steven Galetta, MD, FAAN, Section Editor
}

\section{Editors' note: ALS-specific cognitive and behavior changes associated with advancing disease stage in ALS}

In "ALS-specific cognitive and behavior changes associated with advancing disease stage in ALS," Crockford et al. presented data that show that patients with ALS have impaired cognition and behavior and that these deficits worsen with increasing severity of disease. Raaphorst et al. question whether these changes are the result of frontotemporal dementia or nocturnal hypoventilation due to ALS-associated respiratory muscle weakness. They suggest that it would be helpful to have data on the number of stage 4 patients (patients with respiratory or nutritional insufficiency requiring intervention) who required noninvasive ventilation (NIV) and the extent of each subject's respiratory dysfunction. Abrahams and Crockford reply that $27.78 \%$ of stage 4 patients required NIV, but that there was no significant difference in cognition or behavior and requirement for NIV or lack thereof. However, they agree with Raaphorst et al. that given that respiratory dysfunction is a feature of late-stage ALS and memory impairment is associated with advanced-stage ALS, ventilatory support could potentially improve memory deficits in this population. They emphasize that further research on the relationship between respiratory dysfunction and cognition/behavior in ALS is required, as the current data on this topic come from a single small study.

Ariane Lewis, MD, and Steven Galetta, MD

Neurology ${ }^{\circledR}$ 2019;93:85. doi:10.1212/WNL.0000000000007759

\section{Reader response: ALS-specific cognitive and behavior changes associated with advancing disease stage in ALS}

\author{
Joost Raaphorst (Amsterdam), Emma Beeldman (Amsterdam), Rosanne Govaarts (Amsterdam), \\ Ben Schmand (Amsterdam), and Marianne de Visser (Amsterdam) \\ Neurology ${ }^{\circledR}$ 2019;93:85-86. doi:10.1212/WNL.0000000000007761
}

We read the article by Crockford et al. ${ }^{1}$ with great interest. Approximately $35 \%$ of patients with amyotrophic lateral sclerosis (ALS) have cognitive and behavioral changes, and $15 \%$ have frontotemporal dementia (FTD). The authors found increasing cognitive and behavioral impairment in patients with ALS, in relation to disease severity. We question the extent that these symptoms are ALS specific and reflect spread of the degenerative process in the prefrontal cortex, thus corroborating the link between ALS and FTD.

In ALS, respiratory muscle weakness (e.g., a vital capacity [VC] of $60 \%-80 \%$ of predicted) is associated with cognitive deficits (letter fluency and verbal memory), which improve by noninvasive ventilation (NIV) ${ }^{2,3}$ Behavioral impairment (apathy and hallucinations) may also be due to nocturnal hypoventilation. ${ }^{4}$ Patients in King's clinical stages 1-3 may already have some degree of respiratory involvement (e.g., a VC between $60 \%-80 \%$ without complaints of hypoventilation) associated with cognitive and behavioral impairment. 
To appreciate more fully the important findings, it would be helpful if the authors present relevant data on respiratory assessments for each subgroup and their relation to cognitive and behavioral data. In addition, the proportion of King's stage 4 patients on NIV, if any, may be of interest. $^{5}$

1. Crockford C, Newton J, Lonergan K, et al. ALS-specific cognitive and behavior changes associated with advancing disease stage in ALS. Neurology 2018;91:e1370-e1380.

2. Newsom-Davis IC, Lyall RA, Leigh PN, Moxham J, Goldstein LH. The effect of non-invasive positive pressure ventilation (NIPPV) on cognitive function in amyotrophic lateral sclerosis (ALS): a prospective study. J Neurol Neurosurg Psychiatry 2001;71:482-487.

3. Kim SM, Lee KM, Hong YH, et al. Relation between cognitive dysfunction and reduced vital capacity in amyotrophic lateral sclerosis. J Neurol Neurosurg Psychiatry 2007;78:1387-1389.

4. NICE guideline. Motor neurone disease: assessment and management. In: NICE (National Institute for Health and Care Excellence) [online]. Available at: nice.org.uk/guidance/ng42. Accessed October 1, 2018.

5. Lakerveld J, Kotchoubey B, Kubler A. Cognitive function in patients with late stage amyotrophic lateral sclerosis. J Neurol Neurosurg Psychiatry 2008;79:25-29.

\section{Author response: ALS-specific cognitive and behavior changes associated with advancing disease stage in ALS}

Sharon Abrahams (Edinburgh) and Chris Crockford (Edinburgh)

Neurology ${ }^{\circledR}$ 2019;93:86. doi:10.1212/WNL.0000000000007760

We thank Raaphorst et al. for the comment on our article. ${ }^{1}$ We acknowledged the possible role of respiratory functioning in both the discussion and analysis of data without stage 4 patients; however, $27.78 \%(\mathrm{n}=15)$ of stage 4 patients in this study were on noninvasive ventilation (NIV) at the time of testing for at least 2 weeks. No substantial differences were found in any cognitive or behavioral domain between NIV and non-NIV stage 4 patients.

Few studies examine, in depth, the effect of respiratory dysfunction on cognition/behavior in amyotrophic lateral sclerosis (ALS). Moreover, the evidence that NIV ameliorates neuropsychological dysfunction is based on a single small study $(n=9)$, which found improved functioning in 2 of 6 memory measures, and not on verbal fluency. ${ }^{2}$ The effect of respiratory dysfunction on cognition/behavior is not properly understood, and there is little evidence that this potential effect is transient.

Although we acknowledge the possible moderating role that respiratory insufficiency may play in cognitive dysfunction in ALS, this is not the sole driver of our results. ${ }^{1}$ However, this highlights an important avenue for further research.

1. Crockford C, Newton J, Lonergan K, et al. ALS-specific cognitive and behavior changes associated with advancing disease stage in ALS. Neurology 2018;91:e1370-e1380.

2. Newsom-Davis IC, Lyall RA, Leigh PN, Moxham J, Goldstein LH. The effect of non-invasive positive pressure ventilation (NIPPV) on cognitive function in amyotrophic lateral sclerosis (ALS): a prospective study. J Neurol Neurosurg Psychiatry 2001;71:482-487.

Copyright (c) 2019 American Academy of Neurology

Author disclosures are available upon request (journal@neurology.org). 


\title{
Editors' note: To harvest?: A reality-based ethical dilemma and \\ fictional dialogue
}

In the humanities section article "To harvest?: A reality-based ethical dilemma and fictional dialogue," Drs. Smith and Riggs debate the ethics of harvesting a patient's organs if their surrogate wants the organs donated but reports that the patient did not want to be an organ donor and then later revokes the comment about the patient not wanting to be a donor. They question whether the surrogate's willingness to consent should override the possibility that the patient previously dissented and whether a statement made in passing that an individual does not want to be an organ donor represents informed dissent. Dr. Sethi notes that it is challenging to distinguish between uninformed and informed dissent when one cannot speak directly to the individual involved to ascertain whether they were competent and knowledgeable at the time of the dissent. However, he proposes that it may be helpful to interview the patient's other family members about the issue of dissent. Drs. Smith and Riggs voice appreciation for Dr. Sethi's thoughtful response and comment that it is helpful to contemplate ethical controversies in a hypothetical context to be better prepared to address them in real life.

Ariane Lewis, MD, and Steven Galetta, MD

Neurology ${ }^{\circledR}$ 2019;93:87. doi:10.1212/WNL.0000000000007763

\section{Reader response: To harvest?: A reality-based ethical dilemma and fictional dialogue}

\author{
Nitin K. Sethi (New York) \\ Neurology ${ }^{\circledR}$ 2019;93:87. doi:10.1212/WNL.0000000000007764
}

I read with rapt attention the reality-based ethical dilemma and fictional dialogue on organ harvesting after cardiac death by Drs. Smith and Riggs. ${ }^{1}$ For informed consent to be truly informed, the information provided to the patient is a necessary and obligatory premise. ${ }^{2}$ One may argue that it also depends on the competence and knowledge of the physician or the person providing the information to the patient. Informed dissent too has to meet the above prerequisites. In the authors' fictional case, ${ }^{1}$ it is impossible to determine the quality of the consent or dissent. The mother and close family members should be interviewed in depth in an attempt to ascertain this information. So, will I let the organs be harvested or not? To that question, I would answer, "No."

1. Smith MS, Riggs JE. To harvest?: a reality-based ethical dilemma and fictional dialogue. Neurology 2018;91:666-667.

2. Conti AA. From informed consent to informed dissent in health care: historical evolution in the twentieth century. Acta Biomed 2017; $88: 201-203$

Copyright @ 2019 American Academy of Neurology 


\section{Author response: To harvest?: A reality-based ethical dilemma and fictional dialogue}

Matthew S. Smith (Morgantown, WV) and Jack E. Riggs (Morgantown, WV)

Neurology ${ }^{\circledR}$ 2019;93:88. doi:10.1212/WNL.0000000000007765

We appreciate the rapt attention that our piece ${ }^{1}$ evoked in Dr. Sethi. That is exactly the response we were hoping for in readers. When faced with these kinds of ethical dilemmas, one always wishes for more information. Ultimately, however, in these difficult situations, some decision and course of action (right or wrong) will occur. It is far better to have at least contemplated these issues beforehand, rather than only after one finds him/herself immersed in such issues.

1. Smith MS, Riggs JE. To harvest?: a reality-based ethical dilemma and fictional dialogue. Neurology 2018;91:666-667.

Copyright @ 2019 American Academy of Neurology

\section{CORRECTIONS}

TDP43 pathology in the brain, spinal cord, and dorsal root ganglia of a patient with FOSMN

Neurology ${ }^{\circledR}$ 2019;93:88. doi:10.1212/WNL.0000000000007291

In the article "TDP43 pathology in the brain, spinal cord, and dorsal root ganglia of a patient with FOSMN" by Rossor et al., "first published online January 30, 2019, the headings for table 2 should read "MCV, m/s" and "DML, ms." The authors regret the errors.

\section{Reference}

1. Rossor AM, Jaunmuktane Z, Rossor MN, Hoti G, Reilly MM. TDP43 pathology in the brain, spinal cord, and dorsal root ganglia of a patient with FOSMN. Neurology 2019;92:e951-e956.

\section{Journal Club: Florbetapir imaging in cerebral amyloid angiopathy-related hemorrhages}

Neurology ${ }^{\circledR}$ 2019;93:88. doi:10.1212/WNL.0000000000007523

In the article "Journal Club: Florbetapir imaging in cerebral amyloid angiopathy-related hemorrhages" by Charidimou et al., ${ }^{1}$ the following reference should have been included, detailing a study by Dr. Nicolas Raposo et al.:

Raposo N, Planton M, Péran P, et al. Florbetapir imaging in cerebral amyloid angiopathyrelated hemorrhages. Neurology 2017;89:697-704.

The authors regret the error.

\section{Reference}

1. Charidimou A, Giese AK, Pasi M, et al. Journal Club: Florbetapir imaging in cerebral amyloid angiopathy-related hemorrhages. Neurology 2018;91:574-577. 